\title{
Erratum to: "Icing Effects on Air Transport Operation: State-of-the-art and Prediction Problems" [Russian Meteorology and Hydrology 46(7), 461-473, 2021]
}

\author{
A. R. Ivanova ${ }^{a *}$
}

${ }^{a}$ Hydrometeorological Research Center of the Russian Federation, Bolshoi Predtechenskii per. 11-13, Moscow, 123242 Russia

*e-mail:ivanova@mecom.ru

Received March 9, 2021

Revised March 22, 2021

Accepted April 6, 2021

DOI: $10.3103 / \mathrm{S} 1068373921100113$

The following clarification is necessary to the text about the SFIP index on page 467:

The SFIP index mentioned in the paper $([32,63])$ was originally developed in IPMA (Portugal), tested in ECMWF in 2015 [32], and then adopted and implemented in the MetOffice system in 2019 [63].

The original article can be found online at 10.3103/S1068373921070050. 